\title{
ANALISIS KOMPARASI SWOT STRATEGI 7P DI JASA EVENT ORGANIZER PT. CRATON INDONESIA ANTARA PERUSAHAAN DAN KLIEN DI JAKARTA SELATAN
}

\author{
Sandra Dewi Rosida \\ STIE Unisadhuguna, Jakarta, Indonesia \\ Email : asandra.dewi@ubs-usg.ac.id
}

\begin{abstract}
Abstrak
Pendahuluan : Event organizer sangat membantu pihak-pihak yang membutuhkan jasa tersebut. Bisnis event organizer dapat dikatakan bisnis yang memiliki prospek yang sangat bagus dan menguntungkan, kliennya tidak hanya berasal dari pemerintah atau non pemerintah, tetapi masyarakat kelas menengah ke atas juga menjadi target pemakai jasa event organizer. Maka tidak heran bila bisnis di bidang ini banyak dilirik sejumlah orang.

Tujuan : Penelitian ini dilakukan di PT. Craton Indonesia yang bertujuan untuk mengidentifikasi perbandingan SWOT yang menjadi kekuatan dan kelemahan, yaitu strategi bauran pemasaran $7 \mathrm{P}$ peluang dan ancaman dalam layanan event organizer. Format penelitian ini adalah metode deskriptif dengan analisis data kualitatif.

Metode : Metode deskriptif menitikberatkan pada permasalahan atau fenomena yang ada pada saat penelitian atau yang sebenarnya, kemudian menggambarkan faktafakta permasalahan dan disertai dengan rasional secara akurat.

Hasil : Hasil penelitian menunjukkan ada PT. Craton Indonesia menerapkan bauran pemasaran 7P dengan cukup baik dan perbandingan analisis SWOT perbedaan dan persamaan strategi bauran pemasaran 7P di PT. Kraton Indonesia dengan klien.

Kesimpulan : Proses pemasaran, perancangan, sampai dengan pembuatan event PT. Craton Indonesia sangat mengutamakan kliennya agar klien merasa puas atas jasa yang perusahaan berikan. Analisis komparasi SWOT strategi 7P di jasa event organizer PT. Craton Indonesia antara perusahaan dan klien terdapat perbedaan dan persamaan keunggulan, kelemahan, peluang dan ancaman bagi perusahaan, sebagai berikut.
\end{abstract}

Kata Kunci : Strategi Bauran Pemasaran 7P, Kekuatan, Kelemahan, Peluang, Ancaman

\section{Abstract}

Introduction : Event organizers are very helpful to those who need these services. Event organizer business can be said to be a business that has very good prospects and profitable, its clients not only come from the government or non-government, but the upper middle class is also a target for event organizer service users. So it is not surprising that business in this field is widely seen by a number of people.

Purpose : This research was conducted at PT. Craton Indonesia aims to identify SWOT comparisons that are strengths and weaknesses, namely $7 P$ marketing mix strategies of opportunities and threats in event organizer services. This research format is a descriptive method with qualitative data analysis. 
Method: Descriptive methods focus on problems or phenomena that exist at the time of research or actual, then describe the facts of the problem and accompanied by rationally accurately.

Results : The results of the study showed there was PT. Craton Indonesia applies the $7 P$ marketing mix quite well and swot analysis comparison of differences and similarities of 7P marketing mix strategy in PT. Kraton Indonesia with clients.

Conclusion : The marketing process, design, up to the creation of the event PT. Craton Indonesia prioritizes its clients so that clients feel satisfied with the services provided by the company. Swot comparison analysis of $7 P$ strategy in event organizer services PT. Craton Indonesia between the company and the client there are differences and similarities of advantages, weaknesses, opportunities and threats to the company, as follows.

Keywords : 7P Marketing Mix Strategy, Strength, Weakness, Opportunity, Threat.

\section{Pendahuluan}

Pada saat ini di Indonesia event organizer sudah berkembang sangat pesat terutama di Jakarta dan kota-kota besar, mulai dari konser musik, pameran produk, wedding, seminar, gathering dan sebagainya. Event organizer sangat membantu pihakpihak yang membutuhkan jasa tersebut (Juwita, 2020). Bisnis event organizer dapat dikatakan bisnis yang memiliki prospek yang sangat bagus dan menguntungkan, kliennya tidak hanya berasal dari pemerintah atau non pemerintah, tetapi masyarakat kelas menengah ke atas juga menjadi target pemakai jasa event organizer (Calvin, 2019). Maka tidak heran bila bisnis di bidang ini banyak dilirik sejumlah orang.

Dengan menggunakan jasa event organizer tentunya akan sangat menghemat waktu klien dalam menyelenggarakan suatu acara (Sinaga \& Sembiring, 2021). Biasanya mereka yang menginginkan kegiatan sempurna, tetapi tidak memiliki banyak waktu sehingga membutuhkan kepraktisan dalam mengorganisasikan kegiatan tersebut melalui jasa event organizer (Hermawan \& Brahmanto, 2017) (Hibatullah, 2020). Di dalam bisnis jasa event organizer dan exhibition, jika sebuah event atau exhibition berjalan dengan lancar maka akan berpengaruh kuat terhadap keberhasilan sebuah perusahaan (Malsch \& Salterio, 2016). Klien selalu mengharapkan hasil yang maksimal dari penyedia jasa tersebut. PT. Craton Indonesia merupakan salah satu event organizer dan exhibition di Jakarta yang didirikan pada tahun 2014 yang merupakan anak perusahan dari PT. Ghani Rekatama Mandiri. PT. Craton Indonesia menyediakan beberapa layanan jasa seperti event Organizer dan exhibition yaitu, gathering, festival musik, pameran produk, pameran seni, seminar dan lain-lain terkecuali wedding (Fitria, 2021). Selain layanan tersebut PT. Craton Indonesia memiliki salah satu cara untuk dapat memenangkan persaingan adalah dengan membuat perbedaan layanan yang ditawarkan yaitu, pembuatan website dan aplikasi development perusahaan tersebut juga telah mengahadapi setiap tantangan event serta sering memenangi tender di divisi kementrian (Situmeang, 2016). Walaupun PT. Craton Indonesia tergolong baru di 
Jakarta selatan tetapi sudah cukup banyak event-event yang digarapnya dan klien pun merasa puas akan kerja perusahaan dan meskipun banyak masyarakat yang belum mengetahui akan hadirnya PT. Craton Indonesia di Jakarta Selatan PT. Craton Indonesia berusaha memasarkan produk jasa yang mereka miliki ke seluruh Indonesia (Maisaroh, 2016).

Disini yang menjadikan minat penulis untuk mengetahui strategi $7 \mathrm{P}$ apa yang diterapkan oleh PT. Craton Indonesia hingga cukup banyak perusahaan mempercayakan event yang mereka selenggarakan ditangani oleh PT. Craton Indonesia. Penelitian ini perlu untuk dilakukan agar dapat diketahui dengan jelas mengenai penerapan strategi 7P yang dilakukan oleh PT. Craton Indonesia ditengah persaingan perusahaan penyedia jasa event organizer dan exhibition dan bagaimana komparasi SWOT antara perusahaan dengan klien (Djanuar, 2016).

\section{Metode Penelitian}

Dalam penelitian ini penulis menggunakan jenis penelitian kualitatif (Cresswell, 2017). Teknik penelitian yang dilakukan yaitu penelitian lapangan (field research). Dalam penyusunan skripsi ini, penulis menggunakan dua jenis data yaitu data sekunder dan primer (Malsch \& Salterio, 2016).

\section{Hasil dan Pembahasan}

A. Bauran Pemasaran 7P PT. Craton Indonesia

PT. Craton Indonesia menggunakan strategi bauran pemasaran 7P yang terdiri dari Product, Price, Promotion, Place, People, Process, dan Physical Evidence (Thessalonica, 2020) yang bertujuan untuk mencari keuntungan atau profit dan meningkatkan jumlah klien.

1. Product

Dalam strategi produk PT. Craton Indonesia memiliki banyak pilihan yang memang dibutuhkan oleh kliennya. Produk jasa yang dimiliki PT. Craton Indonesia seringkali memenangkan persaingan hal ini terbuki dan banyaknya event yang ditangani oleh PT. Craton Indonesia. Produk jasa yang ditawarkan oleh PT. Craton Indonesia bertujuan untuk memenuhi kebutuhan yang diperlukan oleh klien. Berikut adalah produk jasa PT. Craton Indonesia:

\section{a. Gathering}

Gathering ini merupakan salah satu produk jasa yang ditawarkan PT. Craton Indonesia. Gathering adalah acara kumpul bersama baik itu ditunjukan bagi perusahaan (Employee Gathering) atau keluarga (Family Gathering) (Giantika, 2018).

\section{b. Grand Opening dan Soft Opening}

Grand Opening adalah kegiatan yang dilakukan ketika adanya sebuah bisnis baru yang telah resmi untuk dibuka secara umum dan dinikmati oleh khalayak publik. Sedangkan Soft Opening adalah sebuah kegiatan yang bertujuan untuk memperkenalkan bisnis baru kepada beberapa orang terpilih 
untuk mencoba kelayakan bisnis tersebut sebelum diperkenalkan ke khalayak public (Nelly Thelma, 2019).

c. Exhibition

Exhibition merupakan salah cara atau media penyebaran informasi, perkenalan sekaligus pemasaran suatu produk, baik berupa jasa ataupun barang.

d. Seminar

Seminar adalah sebuah pertemuan khusus yang tujuannya untuk melakukan studi menyeluruh tentang suatu topik tertentu dengan pemecahan suatu permasalahan yang memerlukan interaksi antara pembicara dan peserta.

e. Festival Musik

Festival musik adalah sebuah pagelaran musik yang memliki sebuah tema dan menghadirkan sejumlah musisi.

f.Pembuatan Web dan Aplikasi

Dalam hal ini PT. Craton Indonesia menangani pembuatan web dan aplikasi berdasarkan permintaan dari klien yang bertujuan agar profil perusahan dari klien tersebut dapat di akses lebih mudah dan lengkap ketika memliki web atau aplikasi (Setiawan, 2019).

g. Event Olahraga

Penyelenggaraan kegiatan olahraga atau sport event merupakan sebuah event yang mempertunjukan sebuah kompetisi dimana beberapa cabang olahraga dipertandingkan.

2. Price

\begin{tabular}{ccc}
\hline No & Nama produk & Harga \\
\hline 1 & Gathering & $\begin{array}{c}200-700 \\
\text { Juta }\end{array}$ \\
\hline 2 & $\begin{array}{c}\text { Grand Opening dan Soft } \\
\text { Openning }\end{array}$ & $200-300 \mathrm{Jt}$ \\
\hline 3 & Exhibition & $\begin{array}{c}250 \text { Juta-1 } \\
\text { Milyar }\end{array}$ \\
\hline 4 & Seminar & $100-300$ Juta \\
\hline 5 & Festival Musik & 800 Juta-4 \\
& Milyar \\
\hline 6 & Pembuatan Aplikasi dan & 30-90 Juta \\
\hline 7 & Web Development & 200-700 Juta \\
\hline
\end{tabular}

3. Promotion

Strategi promosi yang digunakan oleh PT. Craton Indonesia adalah sebagai berikut:
a. Persoal Selling
b. Media Sosial
c. Direct Marketing
d. WOM (Word of Mouth) 
e. Membangun Relasi Partner

\section{Place}

Dalam kegiatan usahanya kantor PT. Craton Indonesia terletak di Gaharu Terrace 22 C, Jl. Terusan Gaharu, Cilandak, Jakarta Selatan 12430.

5. People

People merupakan orang atau karyawan yang melayani ataupun yang merencanakan pelayanan terhadap para klien. Setiap karyawan di PT. Craton Indonesia diharuskan kreatif, jujur, bertanggung jawab, disiplin dan sebagainya.

\section{Process}

Process dari awal penentuan ide hingga terselenggaranya acara. Klien yang membawa sebuah ide membutuhkan pihak yang membantu mereka untuk terbentuknya acara yang klien harapkan yang dibantu oleh pihak event organizer.

\section{Physical Evidence}

Physical Evidence merupakan sejumlah sarana dan prasarana yang dimiliki PT. Craton Indonesia dalam menjalankan aktifitas sehingga berbagai tawaran yang ditunjukan pada pasar sasarannya (Heath et al., 2012).

\section{B. Analisis SWOT PT. Craton Indonesia}

Dari analisis SWOT dapat disimpulkan keunggulan, kelemahan, peluang dan ancaman yang dimiliki PT. Craton Indonesia adalah sebagai berikut:

\begin{tabular}{|c|c|}
\hline 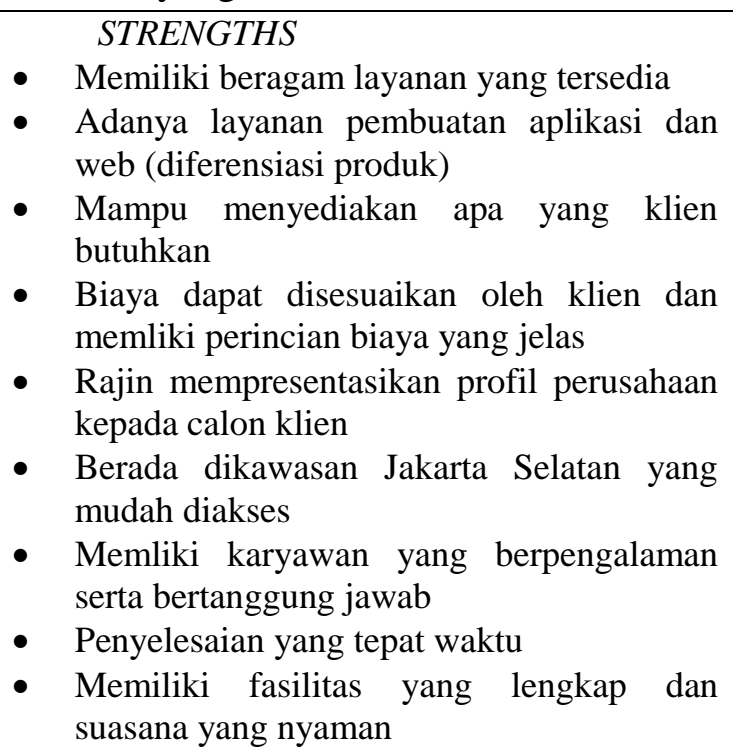 & $\begin{array}{l}\text { WEAKNESSES } \\
\text { - } \quad \text { Banyak klien yang tidak mengetahui } \\
\text { jasa pembuatan aplikasi dan web } \\
\text { - } \quad \text { Tarif yang bisa berubah } \\
\text { - } \quad \text { Kurang aktif dimedia sosial } \\
\text { - } \quad \text { Respon yang lambat dalam } \\
\text { komunikasi via email } \\
\text { - Jalan masuk kedalam komplek } \\
\text { - } \quad \text { Putar balik dari arah jalan TB } \\
\text { - Simatupang terbilang jauh } \\
\text { Kurangnya jumlah karyawan } \\
\text { - Pengerjaan terhambat karena } \\
\text { perubahan rencana dadakan dari } \\
\text { klien } \\
\text { Tidak memiliki area merokok }\end{array}$ \\
\hline $\begin{array}{l}\text { OPPORTUNITIES } \\
\text { - Menambah inovasi produk baru } \\
\text { - Mendatangkan artis internasional } \\
\text { - Klien bisa mendapatkan diskon } \\
\text { - PT. Craton Indonesia memakai sistem } \\
\text { pembayaran online melalui dana, ovo, } \\
\text { gopay dsb } \\
\text { Bisa lebih aktif dimedia sosial } \\
\text { - Membuat strategi promosi dengan cara } \\
\text { yang baru seperti media cetak atau } \\
\text { elektronik }\end{array}$ & $\begin{array}{l}\text { THREATS } \\
\text { - } \quad \text { Munculnya perusahaan baru } \\
\text { - } \\
\text { - } \quad \text { Kemanya biaya tambahan untuk klien } \\
\text { diprediksi yang tidak dapat } \\
\text { - } \text { Karyawan akan mudah kelelahan } \\
\text { - } \quad \text { Perusahaan lain menggunakan } \\
\text { teknologi lebih canggih ketika proses } \\
\text { pembuatan event } \\
\text { Sarana dan prasarana perusahaan } \\
\text { lain lebih modern atau lengkap }\end{array}$ \\
\hline
\end{tabular}


- Pindah lokasi yang berada dipinggir jalan

raya

- Menambah jumlah karyawan

- Lebih mempercepat waktu penyelesaian dari waktu yang ditetapkan

- Membuat area merokok

- Outdoor diperbaiki agar lebih berguna

Hasil dari komparsi antara PT. Craton Indonesia dengan klien: Awalnya adalah sekitar 30\% karena Ride Jakarta dan HaloDoc merupakan klien baru PT. Craton Indonesia pada tahun 2019 ini. Setelah PT. Craton Indonesia mempresentasikan profile perusahaan kepada klien, kemudian mengenal perusahaan lebih dalam dan klien memakai jasa PT. Craton Indonesia dan merasa puas akan kinerjanya maka pengetahuan mengenai PT. Craton Indonesia menjadi $70 \%$.

$$
\text { STRENGTHS WEAKNESSES }
$$

Fleksibelitas dan memprioritaskan klien Jasa layanan tidak tergolong jasa event agar merasa puas, seringnya memenangi tender, memiliki vendor yang bagus, memiliki pengalaman yang baik, DP lebih murah, adanya RAB dan penalanggan dana, selalu mendatangi setiap acara event atau exhibition, selalu menjaga hubungan baik dengan klien, lokasi mudah ditemukan, mudah menggunakan kendaraan umum, miliki kerja tim yang baik, jika ada complain segera diatasi, selalu memberikan saran dan masukan, gedung milik sendiri, mempunyai area outdoor.

organizer berskala internasional, tidak ada event wedding atau ulang tahun, jasa aplikasi dan web belum banyak yang berminat, tidak mengikuti tariff pasar, perbedaan harga pada daerah tertentu, harus mengurangi biaya cost, tidak adanya potongan harga untuk klien baru, jika jalan kaki dari depan komplek cukup jauh, lokasi jauh dari mini market atau tempat makan, terkadang kurangnya peralatan atau perlengkapan, ruangan kurang luas, gedung tidak seperti pada umumnya, tidak ada dapur atau pantry, tidak ada banner perusahaan didepan komplek, tidak ada satpam yang menjaga, kurangnya penghijauan diarea kantor.

OPPORTUNITIES

Melakukan pengembangan memperkenalkan pada jasa aplikasi dan web, klien menyediakan tempat sendiri, klien memberikan bonus, klien menyarankan jasa ke kerabat, teknologi yang semakin canggih, berkembangnya infrastruktur dan sarana, pihak klien membantu saat proses berlangsung, mengurangi resiko revisi kesalahan.

\section{THREATS}

dan Klien menggunakan jasa event organizer lain, teknologi yang semakin canggih, event organizer lain yang lebih banyak layanan dan berpengalaman, tertutupnya peluang akibat pembuatan web dan aplikasi tidak berkembang, biaya tidak sesuai prediksi, harga tempat penyewaan mahal, adanya pengusuran di lokasi tersebut, permintaan perubahan rencana dan spesial dadakan dari klien, adanya musibah bencana alam, sarana dan prasarana rusak, klien memilih meeting diluar.

Persamaan SWOT perusahaan dengan klien 


\section{STRENGTHS}

Memiliki beragam layanan yang tersedia, adanya layanan pembuatan aplikasi dan web (diferensiasi produk), mampu menyediakan apa yang klien butuhkan, biaya dapat disesuaikan oleh klien dan memliki perincian biaya yang jelas, rajin mempresentasikan profil perusahaan kepada calon klien, berada dikawasan Jakarta Selatan yang mudah diakses, memliki karyawan yang berpengalaman serta bertanggung jawab, penyelesaian yang tepat waktu, memiliki fasilitas yang lengkap dan suasana yang nyaman

\begin{tabular}{l}
\hline OPPORTUNITIES \\
Menambah inovasi produk baru, \\
mendatangkan artis internasional, klien bisa \\
mendapatkan diskon, PT. Craton Indonesia \\
memakai sistem pembayaran online melalui \\
dana, ovo, gopay dsb, bisa lebih aktif dimedia \\
sosial, membuat strategi promosi dengan cara \\
yang baru seperti media cetak atau elektronik, \\
pindah lokasi yang berada dipinggir jalan raya, \\
menambah jumlah karyawan, lebih \\
mempercepat waktu penyelesaian dari waktu \\
yang ditetapkan, membuat area merokok, \\
outdoor diperbaiki agar lebih berguna
\end{tabular}

\section{Kesimpulan}

Berdasarkan uraian pembahasan maka berikut kesimpulan tentang hasil penelitian dan analisis komparasi SWOT strategi bauran pemasaran 7P di jasa event organizer. Dapat ditarik kesimpulan bahwa dalam menerapkan strategi bauran pemasaran 7P, sebagai berikut: menyediakan beragam layanan jasa event organizer seperti gathering, grand opening, soft opening, exhibition, seminar, festival musik, event olahraga bahkan PT. Craton Indonesia memiliki diferensiasi produk yaitu pembuatan aplikasi dan web untuk development. Harga yang ditawarkan cukup murah berkisar dari 200 juta - 4 milyar rupiah. PT. Craton Indonesia melakukan promosi melalui personal selling, media sosial, direct marketing, WOM dan juga membangun relasi partner untuk memasarkan layanan produk jasanya. Tempat pemasaran PT. Craton Indonesia berada dilokasi yang cukup strategis yaitu terletak di Gaharu Terrace 22 C, Jl. Terusan Gaharu, Cilandak, Jakarta Selatan. Karyawan PT. Craton Indonesia memiliki bekal yang cukup dalam bidangnya, hal ini dikarenakan karyawan PT. Craton Indonesia cukup berpengalaman dalam pembuatan event. Proses pemasaran, perancangan, sampai dengan pembuatan event PT. Craton Indonesia sangat mengutamakan kliennya agar klien merasa puas atas jasa yang perusahaan berikan. Sarana dan prasarana seperti toilet, tempat parkir, AC, wifi dan sebagainya cukup lengkap untuk menunjang pemasaran. Dari analisis komparasi SWOT strategi 7P di jasa event organizer PT. Craton Indonesia antara perusahaan dan klien terdapat perbedaan dan persamaan keunggulan, kelemahan, peluang dan ancaman bagi perusahaan, sebagai berikut. 


\section{DAFTAR PUSTAKA}

Calvin, Calvin. (2019). Rencana Bisnis Pendirian Usaha Jasa Caplin Event Organizer di Jembatan Dua, Jakarta Utara/Calvin/73150418/Pembimbing: Rita Eka Setianingsih.

Cresswell, J. W. (2017). Research Design: Pendekatan Kualitatif, Kuantitatif, dan Mixed (Edisi Ketiga). Yogyakarta: Pustaka Belajar.

Djanuar, Reza. (2016). Implementasi Strategi Stp Dan $7 p$ Bauran Pemasaran Jasa Pada Suroboyo Carnival Park. Universitas Airlangga.

Fitria, Novia. (2021). Strategi Pemasaran Event Customer Gathering DAV Property Syariah (Penelitian Di DAV Property Syariah). UIN SMH BANTEN.

Giantika, Gan Gan. (2018). Program Employee Relations PT Citra International Underwrites (CIU Insurance) Dalam Upaya meningkatkan Motivasi Kerja. Jurnal Komunikasi, 9(2), 203-210.

Heath, Gregory W., Parra, Diana C., Sarmiento, Olga L., Andersen, Lars Bo, Owen, Neville, Goenka, Shifalika, Montes, Felipe, Brownson, Ross C., \& Group, Lancet Physical Activity Series Working. (2012). Evidence-based intervention in physical activity: lessons from around the world. The Lancet, 380(9838), 272-281.

Hermawan, Hary, \& Brahmanto, Erlangga. (2017). Geowisata: Perencanaan pariwisata berbasis konservasi.

Hibatullah, Ilham. (2020). Strategi Pengembangan Wakaf Produktif di Indonesia dan Malaysia: Pendekatan Analisis SWOT (Studi Komparatif antara Badan Wakaf Indonesia Provinsi Banten dan Wakaf Perak Ar-Ridzuan). UIN SMH BANTEN.

Juwita, Puspa. (2020). Penerapan konsep komunikasi pemasaran Pada event organizer nuansa Dalam menyelenggarakan Acara konser musik. UMSU.

Maisaroh, Eanggi. (2016). Pengaruh Citra Destinasi, Fasilitas Wisata dan Experiental Purchasing terhadap Kepuasan Konsumen (Survei pada Pengunjung Domestik Museum Benteng Vredeburg Yogyakarta). Manajemen-Fakultas Ekonomi.

Malsch, Bertrand, \& Salterio, Steven E. (2016). "Doing good field research": Assessing the quality of audit field research. Auditing: A Journal of Practice \& Theory, $35(1), 1-22$.

Nelly Thelma, Gabriela. (2019). Strategi dan Implementasi Special Event dalam Membangun Brand Image: Studi pada Event Grand Opening The Clinic Beautylosophy Summarecon Bekasi. Universitas Multimedia Nusantara.

Setiawan, Rudy. (2019). Pembangunan Aplikasi Publikasi Event Di Kota Bandung Dengan Memanfaatkan Location Based Services Berbasis Android. Universitas Komputer Indonesia.

Sinaga, Rinita, \& Sembiring, Rizka Ramadhana. (2021). Analisis Peluang Usaha Wedding Organizer Pada Kaum Millennial. Journal of Millennial Community, $3(2), 107-113$.

Situmeang, Ilona V. Oisina. (2016). MODUL MEDIA RELATIONS.

Thessalonica, Casey. (2020). Pengaruh product, price, promotion, place, people dan physical evidence terhadap tingkat kunjungan di kafe Coffee Alley. Universitas Pelita Harapan. 